\title{
THE ACTIVE OXIDATION OF SILICON CARBIDE
}

\author{
Nathan S. Jacobson ${ }^{a}$ and Dwight L. Myers ${ }^{b}$ \\ ${ }^{a}$ NASA Glenn Research Center, Cleveland, OH 44135 USA \\ ${ }^{b}$ Department of Chemistry, East Central University, Ada, OK
}

Abstract. The high temperature oxidation of silicon carbide occurs in two very different modes. Passive oxidation forms a protective oxide film which limits further attack of the SiC:

$\mathrm{SiC}(\mathrm{s})+3 / 2 \mathrm{O}_{2}(\mathrm{~g})=\mathrm{SiO}_{2}(\mathrm{~s})+\mathrm{CO}(\mathrm{g})$

Active oxidation forms a volatile oxide and may lead to extensive attack of the SiC:

$\mathrm{SiC}(\mathrm{s})+\mathrm{O}_{2}(\mathrm{~g})=\mathrm{SiO}(\mathrm{g})+\mathrm{CO}(\mathrm{g})$

Generally passive oxidation occurs at higher oxidant pressures and active oxidation occurs at lower oxidant pressures and elevated temperatures. Active oxidation is a concern for reentry, where the flight trajectory involves the latter conditions. Thus the transition points and rates of active oxidation are a major concern.

Passive/active transitions have been studied by a number of investigators. An examination of the literature indicates many questions remain regarding the effect of impurity, the hysteresis of the transition (i.e. the difference between active-to-passive and passive-toactive), and the effect of total pressure. In this study we systematically investigate, each of these effects.

Experiments were done in both an alumina furnace tube and a quartz furnace tube. It is known that alumina tubes release impurities such as sodium and increase the kinetics in the passive region [1]. We have observed that the active-to-passive transition occurs at a lower oxygen pressure when the experiment is conducted in alumina tubes and the resultant passive silica scale contains sodium. Thus the tests in this study are conducted in quartz tubes.

The hysteresis of the transition has been discussed in the detail in the original theoretical treatise of this problem for pure silicon by Wagner [2], yet there is little mention of it in subsequent literature. Essentially Wagner points out that the active-to-passive transition is governed by the criterion for a stable $\mathrm{Si} / \mathrm{SiO}_{2}$ equilibria and the passive-to-active transition is governed by the decomposition of the $\mathrm{SiO}_{2}$ film. A series of experiments were conducted for active-to-passive and passive-to-active transitions by increasing and decreasing oxygen pressure, respectively. For pure silicon a dramatic difference was found; whereas for SiC the difference was not as great. This may be due to the oxidation of the carbon in SiC which may break down the scale [3].

The third area is the effect of total pressure. In the literature, low oxygen potentials are achieved via either low total pressure or low oxygen pressure in an $\mathrm{O}_{2} / \mathrm{Ar}$ mixture. Both types of experiments are done in this study and the differences are discussed with regard to the presence or absence of a boundary layer.

[1] E. Opila, J. Am. Ceram. Soc. 78 [4], 1107-1110 (1995).

[2] C. Wagner, J. Appl. Phys. 29 [9], 1295-1297 (1958).

[3] Y. Ogura and T. Morimoto, J. Electrochem. Soc. 149 [4], J47-J52 (2002). 